\title{
INFLUENCE OF STORAGE CONDITIONS AND CORROSIVE ENVIRONMENTS ON THE MECHANI- CAL PROPERTIES OF GFRP REBARS
}

\author{
Andrey BENIN ${ }^{1,{ }^{*}}$, Ekaterina BOGDANOVA ${ }^{1}$ \\ ${ }^{1}$ Emperor Alexander I St. Petersburg State Transport University, 190031, 9 Moskovsky pr., Saint \\ Petersburg, Russia. \\ corresponding author: benin.andrey@mail.ru.
}

\begin{abstract}
A trend of applying composite reinforcement in construction industry has been growing in Russia recently: hence, new manufacturing plants have appeared and the volume of sales has increased. However there were not enough experimental studies of the polymer reinforcement chemical stability and the influence of various factors (climate, corrosive environments, nonstationary loading, etc.) on the strength of structures reinforced with polymer rebars. The objective of this investigation was to identify the influence of long-term storage conditions and exposure to corrosive environment (i.e. $5 \%$ $\mathrm{NaCl}$ solution) produced on the mechanical properties of GFRP rebars.
\end{abstract}

\section{Keywords:}

GFRP rebars;

Storage conditions;

Salt brine;

Mechanical properties.

\section{Introduction}

In the middle of the 20th century many countries including the USSR started research in application of non-metallic composite reinforcement bars in capital construction. As composite rebars are not subject to corrosion (unlike metal ones), the most promising way of application was reported in facilities operated within highly corrosive environments. Considering the dielectric properties of composite rebars it was also considered that they could be used in special structures and products requiring dielectric and non-magnetic reinforcement elements. In 1976 Recommendations for Glass Fiber Reinforced Plastic Structural Calculations were issued in the USSR [1]. Nevertheless, the wide introduction of composite reinforcement in construction practice didn't follow because of high cost of GFRP rebars and immaturity of manufacturing technologies in the USSR. At the same time mass adoption of composite rebars began in other countries, mainly in bridge construction and as reinforcement elements for road pavement. It led to the halt of research in composite reinforcement issues in the USSR, whereas in such countries as Japan, Germany, the Netherlands, etc. the study of non-metallic reinforcement applications in various kinds of construction facilities continued and reached impressing results. Carbon and aramid fiber with better mechanical properties got to be used; twisted ropes were integrated in the structures of dozens of motor-road bridges and foot bridges [2]. In the early 2000s the issue of polymer reinforcement was raised again in Russia, resulting in the appearance of numerous manufacturing plants for GFRP and basalt-plastic rebars as well as their use in construction structures and facilities. However there were not enough experimental studies of the polymer reinforcement chemical stability and the influence of various factors (climate, corrosive environments, nonstationary loading, etc.) on the strength of structures reinforced with polymer rebars.

\section{Objective of investigation}

The mechanical properties of reinforcement bars are strongly determined by storage conditions and time the bars are stored in warehouses for construction materials. The Russian norms and manufacturers' specifications allow for transporting and storing polymer reinforcement with diameter of $8 \mathrm{~mm}$ horizontally, in packages or coils, whose minimum diameter is calculated by a special formula. It 
is considered that under these conditions reinforcement retains its consistency and gets into straight position once the fixing clamps are removed. But in reality the coils of reinforcement are moved from one place in a warehouse to another, with its diameter being less than allowed, in order to reduce the storage area and to meet the seasonal customer demand and they are kept vertically in open air (Fig. 1). As a result, minute cracks appear on the surface of reinforcement, which can lead to deterioration of its mechanical properties.

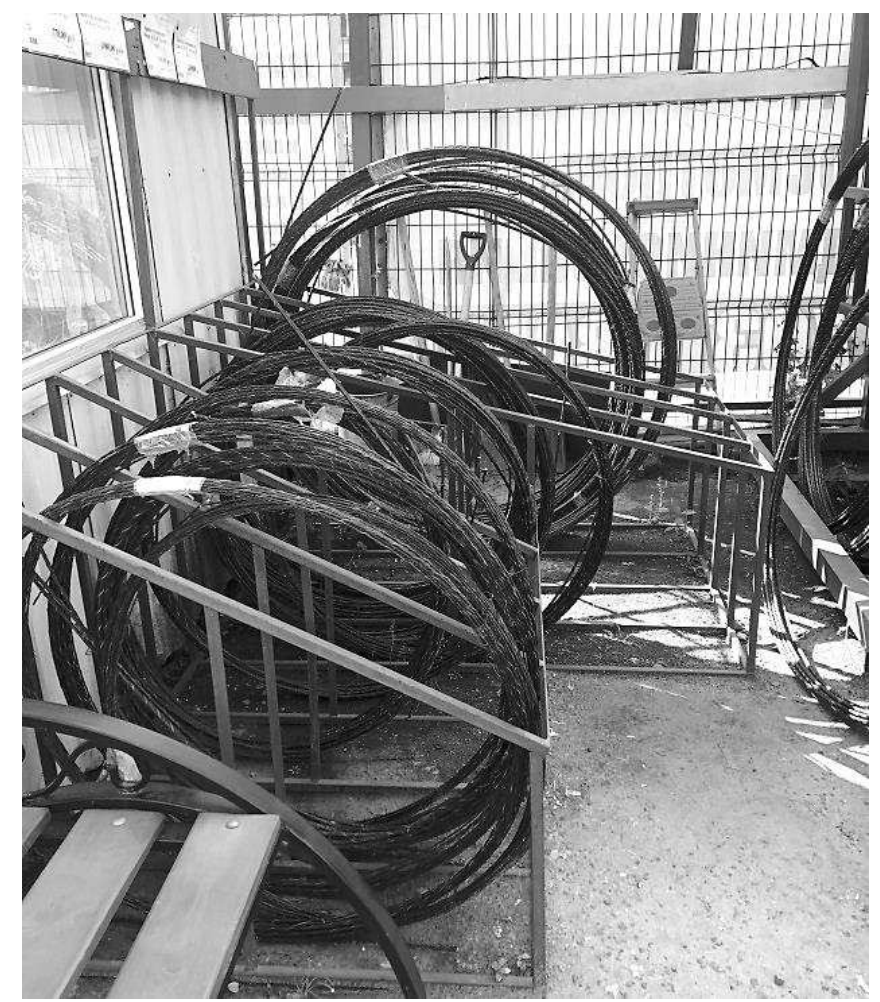

Fig. 1: Example of season storage of GFRP rebars in a warehouse.

Another factor determining the mechanical properties of polymer rebars is their long-term exposure to various environments. It is known that, if used in concrete structures, GFRP rebars are exposed to alkaline medium of wet concrete. There are a number of studies dedicated to this issue [3 - 6]. However the kinds of long-term impact produced by external corrosive environments on the mechanical properties of polymer rebars have not been thoroughly studied yet [7 - 8]; this mainly refers to chemicals widely used in Russia for removing ice from roads, including natural salt $(\mathrm{NaCl})$, sea water, etc. In 2015 we began some investigations of this kind, their results being published in [9].

Thus, the objective of our research was to identify the impact of storage conditions and exposure to saline environments on the mechanical properties of GFRP rebars.

\section{The experiment plan}

In 2015 several samples of GFRP rebars with $8 \mathrm{~mm}$ diameter produced by a single manufacturer and selected directly at the manufacturer's finished goods warehouse from the same batch were taken for research purposes. The rebars were divided into three batches. The first batch was delivered to the lab, a part of it being immediately tested for axial tension, the rest part being stored in the dark room of the lab in bundles at room temperature. The second batch was stored in bundles in a standard unheated manufacturer's warehouse. The third batch was stored at the same warehouse in coils. Rebars were stored for 180 days. After the period of storage had been finished, the second and third batches of rebars were delivered to the lab for testing. The samples from all three batches were then placed into special tanks filled with $5 \% \mathrm{NaCl}$ solution and kept there for 90,180 and 365 days at the temperature of $23^{\circ} \mathrm{C} \pm 2^{\circ} \mathrm{C}$. After that the samples were kept in the atmosphere for one day at room temperature and exposed to testing for axial tension.

The axial tension tests aimed at determining the ultimate tensile strength and modulus of elasticity were conducted in accordance with the Russian standard GOST 31938-2012 "Polymer 
Composite Reinforcement Bars for Concrete Structures" on the Instron universal static testing machine SATEC 1200KN-J3D. The experiment plan is presented in Table 1.

Table 1: The experiment plan.

\begin{tabular}{|c|c|c|c|c|c|c|}
\hline \multirow{4}{*}{$\begin{array}{l}\text { Batch } \\
\text { number }\end{array}$} & \multicolumn{6}{|c|}{ Samples conditioning period } \\
\hline & \multicolumn{3}{|c|}{ Storing at warehouse } & \multirow{2}{*}{\multicolumn{3}{|c|}{$\begin{array}{c}\text { Further conditioning } \\
\text { in } 5 \% \mathrm{NaCl} \text { solution, days }\end{array}$}} \\
\hline & \multirow{2}{*}{$\begin{array}{c}\text { Without } \\
\text { storage }\end{array}$} & \multirow{2}{*}{$\begin{array}{c}\text { At lab warehouse, room } \\
\text { temperature, days } \\
180\end{array}$} & \multirow{2}{*}{$\begin{array}{c}\begin{array}{c}\text { At unheated warehouse, } \\
\text { natural conditions, days }\end{array} \\
180\end{array}$} & & & \\
\hline & & & & 90 & 180 & 365 \\
\hline $\begin{array}{c}1 \\
30 \text { sampl. }\end{array}$ & $\stackrel{+}{+}+1$ & $\begin{array}{c}+ \text { (in bundles) } \\
1.2\end{array}$ & - & $\stackrel{+}{+}$ & $\stackrel{+}{+}$ & $\stackrel{+}{1.6}$ \\
\hline $\begin{array}{c}2 \\
24 \text { sampl. }\end{array}$ & - & - & $\begin{array}{c}+ \text { (in bundles) } \\
2.3\end{array}$ & $\begin{array}{c}+ \\
2.4\end{array}$ & $\begin{array}{c}+ \\
2.5\end{array}$ & $\begin{array}{c}+ \\
2.6\end{array}$ \\
\hline $\begin{array}{c}3 \\
24 \text { sampl. }\end{array}$ & - & - & $\begin{array}{l}+ \text { (in coils) } \\
3.3\end{array}$ & $\begin{array}{c}+ \\
3.4\end{array}$ & $\begin{array}{c}+ \\
3.5\end{array}$ & $\begin{array}{c}+ \\
3.6\end{array}$ \\
\hline
\end{tabular}

Note: «N.M» corresponds to the batch number $(\mathrm{N})$ and type of conditioning $(\mathrm{M})$.

\section{Results of the experiment}

In total, 78 samples of GFRP rebars were tested $(30+24+24$ samples). In the course of the test it was noted that the type of destruction varied for different samples: whereas samples from batches 1.1, 1.2, 1.4, 2.3, 2.4 and 3.3 were destroyed by fiber breaking (Fig. 2a), the rest samples were destroyed by layer separation (Fig. 2b).

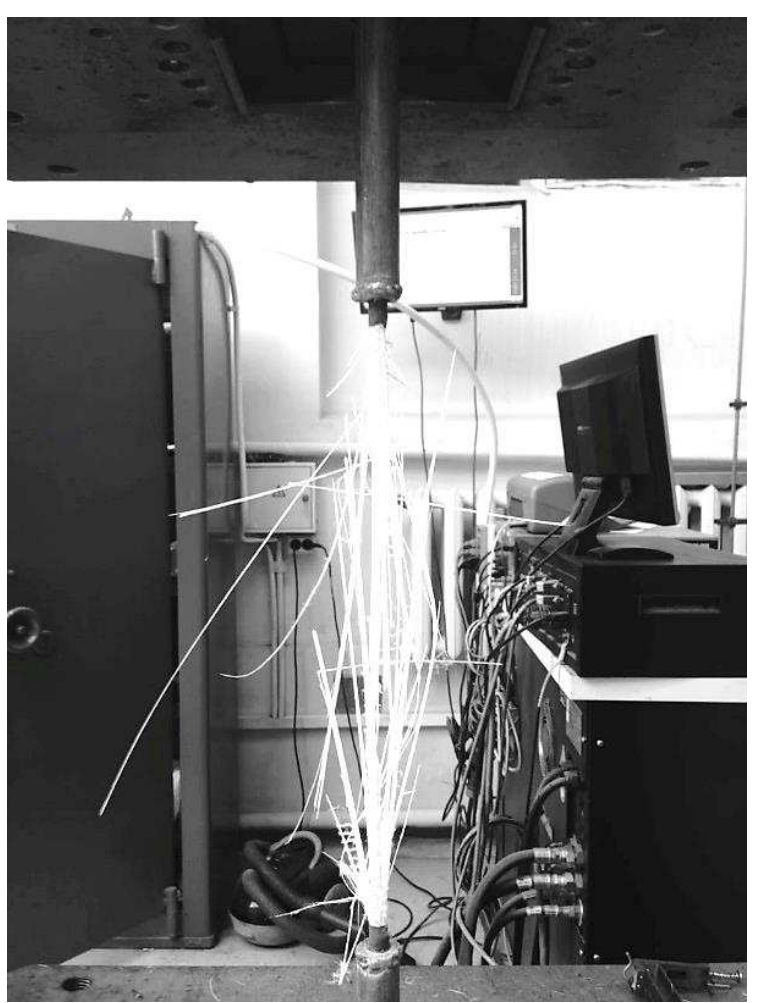

a

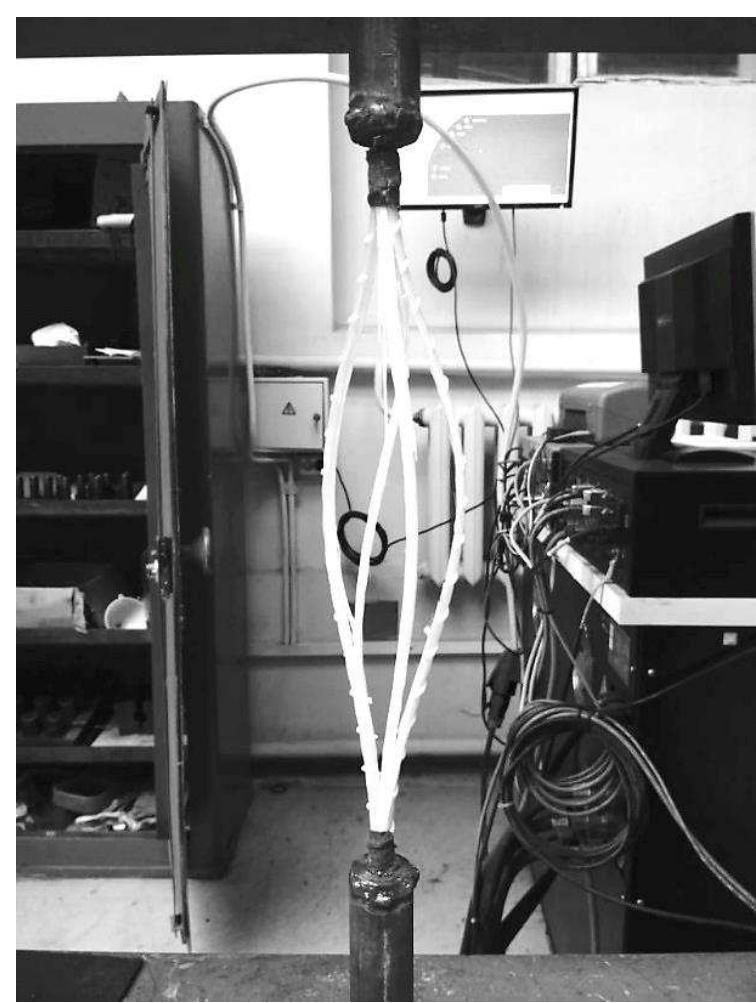

b

Fig. 2: Type of samples destruction caused by axial tension.

The results of the test are presented in Table 2. It also contains standard values for GFRP rebars mechanical properties according to GOST 31938-2012. 
Table 2: Results of GFRP rebars test.

\begin{tabular}{|c|c|c|}
\hline Batch number and serial number & $\begin{array}{l}\text { Ultimate tensile strength } \sigma_{u}, \\
\mathrm{MPa}\end{array}$ & $\begin{array}{l}\text { Modulus of elasticity in tension } E \text {, } \\
\qquad \mathrm{GPa}\end{array}$ \\
\hline Requirements of GOST 31938-2012 & Not less than $800^{*}$ & Not less than $50^{*}$ \\
\hline 1.1 & $1254(100.0 \%)$ & $56(100.0 \%)$ \\
\hline 1.2 & $1250(99.7 \%)$ & $56(100.0 \%)$ \\
\hline 1.4 & $1205(96.1 \%)$ & $55(98.2 \%)$ \\
\hline 1.5 & $1200(95.7 \%)$ & $54(96.4 \%)$ \\
\hline 1.6 & $1200(95.7 \%)$ & $53(94.6 \%)$ \\
\hline 2.3 & $1199(95.6 \%)$ & $54(96.4 \%)$ \\
\hline 2.4 & $1153(91.9 \%)$ & $54(96.4 \%)$ \\
\hline 2.5 & $1123(89.6 \%)$ & $52(92.9 \%)$ \\
\hline 2.6 & $1102(87.9 \%)$ & $49(87.5 \%)^{\star \star}$ \\
\hline 3.3 & $1056(84.2 \%)^{\star \star \star}$ & $51(91.1 \%)$ \\
\hline 3.4 & $1035(82.5 \%)^{\star \star *}$ & $46(82.1 \%)^{\star *}$ \\
\hline 3.5 & $998(79.6 \%)^{\star \star \star}$ & $44(78.6 \%)^{\star \star}$ \\
\hline 3.6 & $989(78.6 \%)^{\star \star \star}$ & $44(78.6 \%)^{\star \star}$ \\
\hline
\end{tabular}

Notes: * These parameters are the minimum allowed values; in the documentation for the tested rebars the manufacturer declares values of $\sigma_{u}$ not less than $1100 \mathrm{MPa}$ and $E$ not less than $50 \mathrm{GPa}$; ${ }^{*}$ The values of modulus of elasticity are less than the allowed minimum; ${ }^{* *}$ The values of ultimate tensile strength are less than declared by manufacturer.

\section{Conclusion}

1. The experiment showed that in case of long-term storage of GFRP reinforcement coils, even if the requirements for the minimum coil diameter and the storage conditions are observed, the mechanical properties (ultimate tensile strength and modulus of elasticity in tension) decrease by $10-15 \%$ due to formation of minute cracks on the rebar surface. This factor should be thoroughly considered if the coils with reinforcement are stored at commercial enterprises rather than at manufacturer's warehouse, which means that the manufacturer cannot monitor the storage conditions.

2. If GFRP rebars are used in corrosive environments (for instance, chemicals for removing ice from roads, etc.), it is necessary to account for the decrease of rebars' mechanical properties (ultimate tensile strength and modulus of elasticity). Moreover, if the rebars were stored in coils for a long time before being used, their mechanical properties (especially modulus of elasticity) can drop below the minimum values allowed by the standards (in our test case the modulus of elasticity dropped down by more than $21 \%$ ). This fact is especially pressing because manufacturers in Russia tend to produce rebars with minimum allowed values of modulus of elasticity, which reduces the safety factor of their products.

3. It is necessary to conduct some more research in the issue of the extent and the velocity of GFRP rebars mechanical properties degradation under combined conditions of corrosive environment, mechanical stress and alternating temperature impact.

4. It is recommended to introduce an obligatory procedure of additional monitoring of the reinforcement mechanical properties after it is has been stored for a long period of time (especially in coils). This is caused by the fact that manufacturers have no opportunity to control the reinforcement storage conditions at the commercial enterprises.

\section{References}

[1] Recommendations for Glass Fiber Reinforced Plastic Structural Calculations. P - 16 - 78, Moscow, 1976, 21 p. (in Russian).

[2] STEPANOVA, V. F. - STEPANOV, A. YU. - ZHIRKOV, E. P.: Polymer Composite Reinforcement Bars. Moscow, 2013, 200 p. (in Russian). 
[3] BLAZNOV, A. N. et al.: On Chemical Stability of GFRP Rebars. Design and Construction in Siberia, \#3, (21), 2003, pp. 34 - 37 (in Russian).

[4] DALINKEVICH, A. A. et al.: Basalt Fiber Aging Kinetics in Alkaline Environment. Plastic Masses, \#3, 2002, pp. 7 - 10 (in Russian).

[5] Report Concerning the Test Regard to the Alkaline Durability of an Anchoring System Out Plastic Reinforced with Glass Fiber Concerning Three-Wythed Façade Panels According to the DEHA-TM System, Ramm, November, 1992.

[6] Report Concerning the Test Regard to the Alkaline Durability of an Anchoring System Out Plastic Reinforced with Glass Fiber Concerning Three-Wythed Façade Panels According to the DEHA-TM System, Ramm, January, 1993.

[7] NKURUNZIZA, G. - DEBAIKY, A. - COUSIN, P. - BENMOKRANE, B.: Durability of GFRP bars. A critical review of the literature. Progress in Structural Engineering Materials, Vol. 7, 2005, pp. 194 209.

[8] WANG, J. - GANGARAO, H. - LIANG, R. - ZHOU, D. - LIU, W. - FANG, Y.: Durability of glass fiber-reinforced polymer composites under the combined effects of moisture and sustained loads. Journal of Reinforced Plastics and Composites, Vol. 34, No. 21, 2015, pp.1739 - 1754.

[9] BENIN, A. - SEMENOV, S. - BOGDANOVA, E.: Influence of long-term exposure in the concrete of FRP rebars on bond characteristics. Solid State Phenomena, Vol. 263, SSP, 2017, pp. 3 - 6. 